\title{
Comparison of gene expression of mitogenic kinin path in adherent and non-adherent CD 34-stem cells using oligonucleotide microarrays
}

\author{
Rafal Stojko ${ }^{1}$, Andrzej Witek ${ }^{1}$, Joanna Glogowska ${ }^{2}$, Urszula Mazurek ${ }^{2}$, \\ Grzegorz Chromy $^{1}$, Krzysztof Wilk ${ }^{1}$, Łukasz Witek ${ }^{1}$, Monika Bojdys-Szyndlar ${ }^{1}$, \\ Krzysztof Machaj ${ }^{3}$, Zygmunt Pojda ${ }^{3}$
}

${ }^{1}$ Gynecology and Obstetrics Department, Medical University of Silesia, Katowice, Poland

${ }^{2}$ Department of Molecular Biology, Medical University of Silesia, Sosnowiec, Poland

${ }^{3}$ Department of Experimental Hematology, Warsaw, Poland

\begin{abstract}
One of the more interesting cells present in the umbilical cord blood - as far as their potential clinical use is concerned - are stem cells not presenting the CD34 antigen.. These are the pluripotential cells with their biological properties similar to mesenchymal stem cells, with the ability to differentiate into such tissue types as bone, cartilage, nervous (to some extent), glia and muscle. The authors compared the activity of genes coding the proteins in mitogenic signal paths activated by kinin receptors using oligonucleotide microarrays in adherent and non-adherent CD 34- cells derived from umbilical cord blood. In the linear regression model with a 95\% prognosis area for differentiating genes outside this area, the following genes were selected: c-jun (present in 3 isoforms) and c-fos. The fos and jun genes create the AP-1 transcriptive factor which regulates the expression of genes taking part in numerous cellular processes, including the cell cycle and mitosis. The obtained results shed some light on the molecular processes behind the MSC proliferation and are a starting point for further studies on the mesenchymal stem cell biology.
\end{abstract}

Keywords: Mesenchymal stem cells - Umbilical cord blood - Kinin receptors - Microarrays

\section{Introduction}

Umbilical cord blood (UCB) is a valuable source of more better studied hematopoietic stem cells with a wide application in cell-based therapy [1-6]. Additionally, UCB is also a source of non-hematopoietic cells called mesenchymal stem cells (MSC) [7-9]. They are adherent cells with a morphology similar to fibroblast cells and an expression of a characteristic panel of surface markers and which lack the expression of CD 34 antigen. These cells - with their ability to differentiate into such tissue types as bone, cartilage, fat, muscle and probably also nervous - constitute an attractive alternative source of mesenchymal stem cells of a high therapeutical potential.

Correspondence: R. Stojko, Gynecology and Obstetrics Department, Medical University of Silesia, Medykow 14, 40-952 Katowice, Poland; tel.: (+4832) 7894731, fax.: (+4832) 7894732, e-mail: rstojko@slam.katowice.pl
Mesenchymal stem cells which are CD34 negative have not only the ability to differentiate into different types of tissues, but they can also self-replicate, which is one of the fundamental properties of a stem cell. Studies concentrating on finding the molecular basis of proliferating properties led to the discovery of the Oct3/4 transcriptive factor [10], LIF activating Stat3 [11-13] and Nanog [14,15] in embryonic stem cells.

Nowadays more better studies are based on the analysis of genes expression using oligonucleotide microarrays which leads to defining the so-called stem cell molecular signature [16,17]. The proliferating potential of CD 34- stem cells - as well as other stem cells - is sustained by suitably activated constellations of genes; however, as of today, no unambiguously determined molecular factor responsible for SC selfreplication has been found.

Having in mind the above, the authors decided to compare two populations of adherent and non-adherent CD 34- cells derived from umbilical cord blood. 
The authors compared the activity of genes coding the proteins of mitogenic signal paths activated by kinin receptors using oligonucleotide microarrays. Kinin receptors are numerously found in human cells and among others - also play a role in the regulation of cells proliferation.

Knowing that mesenchymal stem cells are adherent and have a high proliferating potential, the authors looked for a molecular factor in the mitogenic kinin path which would better characterize this population of cells and which would become the mesenchymal stem cell signature and as a result help better understand the mechanisms controlling the proliferating process of the CD 34- stem cells.

\section{Materials and methods}

The material for studying the expression of genes using oligonucleotide microarrays consisted of cultures of CD34- cells with different adhesive properties. The adherent cells were marked CD34P, while the non-adherent - CD34-NP. Total RNA was extracted from the cultures.

Extraction of CD 34-cells from umbilical blood. The collected umbilical blood was diluted with PBS (Gibco) and then carefully layered on Ficoll at the ratio of 2:1 and centrifuged for $40 \mathrm{~min}$. at $400 \mathrm{x} \mathrm{G}$ in $20^{\circ} \mathrm{C}$. The obtained lymphocytic surface coat was suspended in medium with an addition of serum and centrifuged again for $10 \mathrm{~min}$. at $200 \mathrm{x} \mathrm{G}$ in $20^{\circ} \mathrm{C}$. This action was repeated twice. The cells were divided into CD34+ and CD34- fractions with the Progenotor Cell Isolation Kit and the Mini\&MidiMACS Starting Kit. The CD34 cells count was performed by the cells fluorescence check upon the incubation with monoclonal antibodies anti-CD34 (BD) coupled with IgG1 (BD) antibodies. Cells' vitality was assessed with a fluorescence microscope upon their marking with etidine bromide and acridine orange. The CD34 cells count was performed with flow cytometry upon incubation with monoclonal antibodies anti-CD34 (BD) coupled with phycoerythrin (PE) or with IgG1 antibodies. The analysis was performed with FACSCalibur (BD) and CELLQuest (BD) software.

Culture establishment. The isolated fractions were used to start cultures in expansion medium. Cells were allowed to adhere overnight and nonadherent cells were washed out and cultured separately in new flasks. Medium changes were carried out once a week thereafter. Expansion medium consists of Iscove modified Dulbecco medium (IMDM) and 20\% fetal bovine serum (FBS) supplemented with $10 \mathrm{ng} / \mathrm{mL}$ bFGF, $100 \mathrm{U}$ penicillin, $1000 \mathrm{U}$ streptomycin, and $2 \mathrm{mM}$ L-glutamine (Gibco).

Total RNA extraction from cell culture. RNA extraction from CD34 cell culture was performed with a total RNA extraction kit (Total RNA Prep Plus, A\&A Biotechnology) based on the modified Chomczynski and Sacchi method (Chomczyński P, Sacchi N, 1987). In the initial phase, cells were diluted and the endogenic RNases inactivated with phenol. After the addition of chloroform, the mixture was centrifuged and the TNA was precipitated with isopropanol. Next the mixture was centrifuged for $20 \mathrm{~min}$. at 13 $000 \mathrm{rpm}$, the supernatant was decanted and the RNA sediment was washed twice with $75 \%$ ethanol. Upon drying, the sediment was stored at $-70^{\circ} \mathrm{C}$ until analysis.

RNA extracts quality analysis. RNA extracts were quality assessed with agar electrophoresis in $1 \%$ agar gel with an addition of etidine bromide $(0.5 \mathrm{mg} / \mathrm{ml})$ in the SUBMINI device (Kucharczyk). $5 \mu \mathrm{l}$ of extract was mixed with $3 \mathrm{ml}$ of loading solution $(0.05 \% \mathrm{w} / \mathrm{v}$ bromophenol blue, $60 \%$ glycerol $)$ and warmed at $65^{\circ} \mathrm{C}$ for $4 \mathrm{~min}$. Upon separation, electrophoregrams were assessed with the UV transilluminator $(\lambda=260 \mathrm{~nm})$.

RNA extracts quantity analysis. Total RNA extracts were assessed with the spectrophotometric assessment of RNA concentration (Gene Quant II, Pharmacia). The spectrophotometric assessment of extracts included the absorbency check with wave lengths of 230,260, 280 and $320 \mathrm{~nm}$, and next the determination of the A260/A280 ratio and protein contents. The absorbency value for the wale length of $260 \mathrm{~nm}$ was used to determine the RNA concentration, assuming that the result in a cuvette of optic path of 1 $\mathrm{cm}$ equal $1 \mathrm{OD} 260$ corresponds to the concentration of $40 \mathrm{mg}$ of RNA per $1 \mathrm{~cm}^{3}$ of extract.

\section{Microarrays - methodology}

General assumptions. The studied material consisted of TNA extracted from cell cultures with the TRIzol reagent. The isolated RNA was then purified with RNeasy Total RNA Mini Kit and etched with DNasis. Approximately $8 \mu \mathrm{g}$ of total RNA was used for the synthesis of two-thread cDNA. It was followed by the cRNA synthesis, marked with biotin. Biotinized cRNA was then fragmented and hybridized with Test3 and HG U133A microarrays (Affymetrix) and marked with the streptavidin-phycoerythrin complex. The fluorescence intensity was analyzed with the GeneArray Scanner G2500A. The quantity and quality of total RNA, cDNA and cRNA were assessed spectrophotometrically and with electrophoresis in $1 \%$ agar gel. The obtained results were analyzed with RMA Express and Luster 3.0 software.

\section{Stage I}

Purification of RNA extract with RNase Mini Kit. Upon measuring the concentration of the RNA extract, it was brought to the volume of $100 \mu \mathrm{l}$ with RNase-free water; next, $350 \mu \mathrm{l}$ of RLT buffer with $\beta$-mercaptoethanol and $250 \mu \mathrm{l}$ of $96 \%$ ethanol was added, the mixture was stirred by pipetting, and then placed on a column and centrifuged for 15 seconds at $12000 \mathrm{rpm}$. The filtrate was discarded and the column placed in a new tube; $350 \mu 1$ of RW1 was added and then centrifuged for 15 seconds at 10 000-12 000 rpm. The next stage consisted of etching with DNase. $70 \mu \mathrm{l}$ of RDD buffer was added to a tube containing $10 \mu \mathrm{l}$ of DNase. The mixture was placed on a column membrane and left etching for 15 min. in room temperature. Next, $350 \mu 1$ of RW1 was added, the old filtrate was drenched and centrifuged for 15 seconds at $12000 \mathrm{rpm}$. The filtrate was discarded and $500 \mu 1$ of RPE was added on the column. The extract was centrifuged for 1 minute at $14000 \mathrm{rpm}$, then the column was rotated and the centrifuging was repeated in the same conditions. Upon centrifuging, the column was moved to a new tube, $30 \mu \mathrm{l}$ of $\mathrm{H}_{2} \mathrm{O}$ was added and left for 10 minutes. Upon centrifuging, $20 \mu \mathrm{H} \mathrm{H}_{2} \mathrm{O}$ was added, left for a few minutes and centrifuged again. Upon purification, the concentration of obtained extracts was assessed.

\section{cDNA synthesis}

1st thread synthesis. In order to obtain the first cDNA thread, 10 $\mu 1$ of RNA extract was mixed with 21 of 100 pM starter T7-oligo $(\mathrm{dT})_{24}$ (5'-GCC AGT GAA TTG TAA TAC GAC TCA CTA TAG GGA GGC GG-3'); the mixture was incubated at $70^{\circ} \mathrm{C}$ for $10 \mathrm{~min}-$ utes and placed on ice. Next, the following were added to the reaction: $4 \mu 1$ of $5 \times$ First Strand Buffer, $2 \mu 1$ of 0.1 M DTT and $1 \mu 1$ of $10 \mathrm{mM}$ dNTPs. Upon 2 minutes of preincubation at $45^{\circ} \mathrm{C}, 1 \mu \mathrm{l}$ (200 U) of reverse transcriptase Supercscript II (Life Technologies) was added to the mixture and incubated for another hour.

2nd thread synthesis. In order to obtain the second cDNA thread, $30 \mu \mathrm{l}$ of $5 \times$ Second Strand Buffer, $91 \mu 1$ of RNase-free water, $3 \mu 1$ 
of $10 \mathrm{mM}$ dNTPs, $4 \mu \mathrm{l}(40 \mathrm{U})$ of $E$. coli DNA Polymerase I, $1 \mu \mathrm{l}$ $(10 \mathrm{U})$ of $E$. coli DNA Ligase and $11(2 \mathrm{U})$ of RNase $\mathrm{H}$ were added to the mixture. The mixture was incubated for 2 hours at $16^{\circ} \mathrm{C}$. Next $2.5 \mu \mathrm{l}(10 \mathrm{U})$ of T4 DNA Polymerase I was added to the mixture and incubated at $16^{\circ} \mathrm{C}$ for another 5 minutes. The reaction was stopped by adding $10 \mu \mathrm{l}$ of $0.5 \mathrm{M}$ EDTA and the two-thread cDNA was extracted with the phenol/chloroform method. The liquid phase was separated with Phase Lock Gel tubes.

\section{Stage II}

Precipitation. Upon night-long freezing at $-20^{\circ} \mathrm{C}, 0.3 \mu \mathrm{l}$ of Palet Paint was added top the mixture and centrifuged for $20 \mathrm{~min}$. at $12000 \mathrm{rpm}$. in room temperature; the supernatant was collected and the sediment was washed twice with $70 \%$ ethanol $(500 \mu 1)$ and centrifuged for $5 \mathrm{~min}$. at $12000 \mathrm{rpm}$; the sediment was well dried and diluted in $12 \mu 1$.

cRNA synthesis. The template for biotinylated cRNA synthesis was $10 \mu \mathrm{l}$ of ds cDNA to which the following were added: $12 \mu \mathrm{l}$ of RNase-free water, $4 \mu \mathrm{l}$ of hybridization buffer, $4 \mu \mathrm{l}$ of ribonucleotides marked with biotin, $4 \mu \mathrm{l}$ of DTT, $4 \mu \mathrm{l}$ of RNases inhibitor and $2 \mu \mathrm{l}$ of T7 polymerase. The mixture was placed at $37^{\circ} \mathrm{C}$ for 5 hours and stirred every $30 \mathrm{~min}$.

cRNA purification. Upon 5 hours of incubation, cRNA was purified. $60 \mu \mathrm{l}$ of $\mathrm{H}_{2} \mathrm{O}, 350 \mu \mathrm{l}$ of RLT buffer and $250 \mu \mathrm{l}$ of $96 \%$ ethanol were added to $40 \mu \mathrm{l}$ of mixture. The new mixture was then placed on a column and centrifuged twice for 15 seconds at $10000 \mathrm{rpm}$. Next $500 \mu \mathrm{l}$ of RPE buffer was added on the column and centrifuged twice for 15 seconds at $10000 \mathrm{rpm}$. The column was incubated with water and then the concentration of cRNA was assessed.

\section{Stage III}

cRNA fragmentation. $16 \mu \mathrm{g}$ of cRNA was used for fragmentation. The mixture was centrifuged and placed at $94^{\circ} \mathrm{C}$ for $35 \mathrm{~min}$. and then placed on ice. The result of fragmentation was checked on $1 \%$ agar gel.

Assessment of cDNA synthesis, biotinylated cRNA and cRNA upon fragmentation with the electrophoresis technique in agar gel. The regularity of cDNA synthesis, biotinylated cRNA and cRNA upon fragmentation was assessed with electrophoresis in agar gel with an addition of etidine bromide. The obtained electrophoregram of distribution of above-mentioned products made it possible to proceed to the next stage of analysis.

Preparation of hybridization cocktail. To prepare the hybridization cocktail, $37.5 \mu 1$ of fragmented cRNA was used and the following were added: $5 \mu \mathrm{l}$ of hybridization control B2, $15 \mu \mathrm{l}$ of eukaryotic control, $3 \mu \mathrm{l}$ of Herring Sperm, $3 \mu \mathrm{l}$ of acetylated BSA, $150 \mu \mathrm{l}$ of hybridization buffer and $86.5 \mu \mathrm{l}$ of water. The cocktail was warmed for 5 minutes at $99^{\circ} \mathrm{C}, 5$ minutes at $45^{\circ} \mathrm{C}$ and centrifuged for 5 minutes at $14000 \mathrm{rpm}$.

Application of the cocktail on the chip. The microarray was warmed to the room temperature and then $100 \mu 11 \times$ of hybridization buffer was applied. The microarray was placed in the hybridization oven for 10 minutes. Next, the buffer was removed from the microarray and $200 \mu \mathrm{l}$ of the hybridization cocktail was applied. The microarray was placed in the hybridization oven for 16 hours at $45^{\circ} \mathrm{C}$.

\section{Stage IV}

Rinsing of microarray. After the 16-hour hybridization the microarray was rinsed and scanned with the GeneArray Scanner G2500A

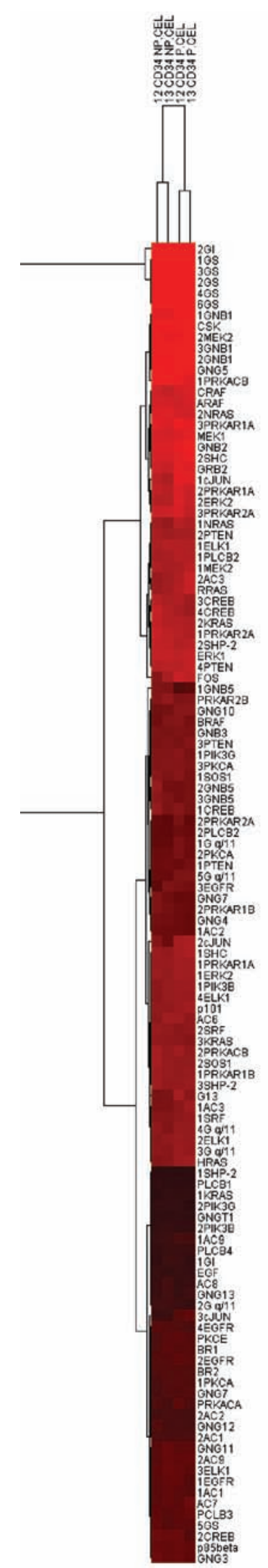

Fig. 1. Grouping of the stem cell cultures on the basis of the expression profile analysis of 120 transcripts of genes coding peptides of mitogenic signal paths activated by the receptors for kinins. 
Table 1. The symbol and ID of Two genes differentiating the adherent cells from the non-adherent ones.

\begin{tabular}{|c|c|c|c|c|}
\hline No. & Symbol & ID & mRNA & Sequence \\
\hline 1 & c-jun & 201464_x_at & $2478-2710$ & $\begin{array}{c}\text { GeneBank NM_002228.3 } \\
\text { mRNA - 3338 pz }\end{array}$ \\
\hline 2 & c-jun & 201465_s_at & $1718-2056$ & \\
\hline 3 & c-jun & 201466_s_at & $2873-3255$ & \\
\hline 4 & Fos & 209189_at & & \\
\hline
\end{tabular}

\section{Results}

The genes expression profile (transcriptom) for two adherent and two non-adherent stem cells was marked with the oligonucleotide microarray technique HG_U133A (Affymetrix).

Literature reports were used to determine the numbers of transcripts of the so-called ID genes that code the peptides of the mitogenic signal paths activated by the receptors for kinins from 22283 transcripts, whose transcription activity can be analyzed by means of the oligonucleotide microarray HG U133A Affymetrix. Out of the group of mRNA genes that code peptides of mitogenic signal paths activated by the receptors for kinins, 120 transcripts were selected for further study.

The fluorescence signal of the analyzed transcripts was a base for defining the transcriptive activity profile of the genes in the four cultures of stem cells. The genes expression profile marked by means of the oligonucleotide microarray technique was analyzed after standardizing the fluorescence values for all analyzed experiments where the RNA express program was applied. The results obtained through the oligonucleotide microarray technique were grouped with the Cluster 3.0 software through the hierarchical clusterization method, using the Euclidean distance measure and the agglomeration method: average connections.

Next, in order to determine the genes differentiating the cultures of adherent and non-adherent stem cells, the model of linear regression was established. By means of this method two genes were determined to code the transcription factors cjun and fos.

\section{Discussion}

The enthusiasm around the mesenchymal stem cell resulting from its special characteristics, such as a high proliferation potential, relatively easy isolation, genetic stability, repeatable characteristics in different laboratories, its regeneration ability in the environment of different tissues makes the MSC a population of choice for widely-understood tissue engineering. The fundamental condition for the full exploitation of the MSC CD34- biological potential lays in the ability to maintain their culture in a state of non-differentiation, i.e. in a primitive, pluripotential state, as well as the ability of their multiplication and orientation of their differentiation into a chosen tissue.

However, the level of knowledge of the MSC remains insufficient. The application of this cell population for clinical purposes requires a deeper understanding of the mechanisms of its basic processes, such as self-replication vs. differentiation.

The microarray provides the possibility of studying the expression of not only one gene during one experiment, but also tens of thousands of genes simultaneously. This enables to obtain the total picture of the condition of the cell at any given moment and also provides an insight into the regulatory mechanisms of the cell.

During the laboratory proceedings, the adherent CD 34- cells, which correspond to MSC in terms of phenotype, showed a change of the transcriptive activity of c-jun and fos genes, which - in a determined linear regression model with a $95 \%$ prognostic area diversified both cell populations. C-jun and c-fos genes are protooncogenes, also defined as the immediate-early genes, because their expression is early induced as a response to a wide spectrum of stimulating factors to facilitate a cell's adaptation to the environment $[18,19]$. The fos and jun genes together create the dimeric complex AP-1. Being a transcriptive factor through the activation and inhibition of the wide spectrum of genes, AP-1 regulates numerous physiological processes, including - first and foremost - cell proliferation, differentiation and organogenesis [20,21]. It is also a necessary factor of various pathological processes, e.g. tumorogenesis $[22,23]$.

However, the actual role of the c-fos and c-jun genes in the MSC has not been defined so far. The studies conveyed on the mouse embryonic stem cells where both copies of c-fos were inactivated showed that there were no changes in viability, proliferating potential and differentiation of these cells [24,25]. Similarly, the inactivation of both copies of c-jun gene in the mouse embryonic stem cells via homological recombination did not show any significant differences in the process of proliferation and differentiation. Yet, the same study showed that subcutaneous application of such recombined mouse embryonic stem cells led to 


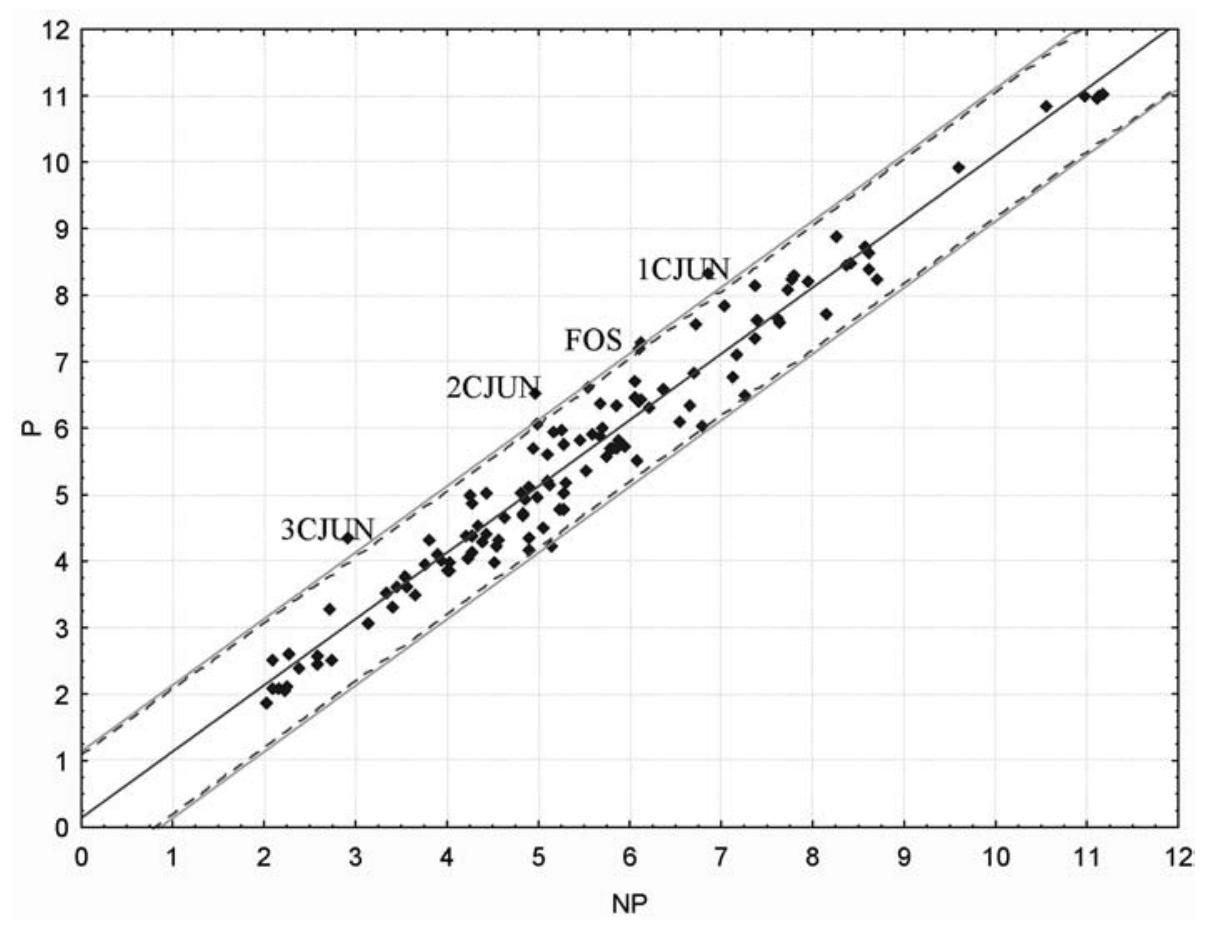

Fig. 2. Genes differentiating the adherent cells from the non-adherent ones, chosen on the basis of the linear regression analysis; red lines show the 95\% prognosis area, while green lines show a double increase or decrease of expression. a drastic reduction in the creation of malignant teratomas [26].

To sum up, according to available sources, the significance of activity of the genes taking part in the MSC mitogenic kinin path has not been studied yet. Therefore the role and significance of the fos and jun genes in the process of proliferation and differentiation of human MSC requires further investigation and study.

\section{References}

[ 1] Cohena Y, Nagler A. Hematopoietic stem-cell transplantation using umbilical cord blood. Leuk Lymphoma. 2003;44:12871299.

[2] Long GD, Laughlin M, Madan B et al. Unrelated umbilical cord blood transplantation in adult patients. Biol Blood Marrow Transplant. 2003;9:772-780.

[ 3] Ooi J, Iseki T, Takahashi S et al. Unrelated cord blood transplantation for adult patients with de novo acute myeloid leukemia. Blood. 2004;103:489-191.

[4] Frassoni F, Podesta M, Maccario R et al. Cord blood transplantation provides better reconstitution of hematopoietic reservoir compared with bone marrow transplantation. Blood. 2003;102:1138-1141.

[ 5] Bhattacharya A, Slatter M, Curtis A et al. Successful umbilical cord blood stem cell transplantation for chronic granulomatous disease. Bone Marrow Transplant. 2003;31:403-405.

[ 6] Laughlin MJ, Barker J, Bambach B et al. Hematopoietic engraftment and survival in adult recipients of umbilical-cord blood from unrelated donors. N Engl J Med. 2001;344:18151822.

[7] Erices A, Conget P, Minguell JJ. Mesenchymal progenitor cells in human umbilical cord blood. Br J Haematol. 2000; 109:235-242.

[ 8] Goodwin HS, Bicknese AR, Chien SN et al. Multilineage differentiation activity by cells isolated from umbilical cord blood: expression of bone, fat, and neural markers. Biol Blood Marrow Transplant. 2001;7:581-588.

[9] Romanov YA, Svintsitskaya VA, Smirnov VN. Searching for alternative sources of postnatal human mesenchymal stem cells: candidate MSC-like cells from umbilical cord. Stem Cells. 2003;21:105-110.

[10] Nichols J, Zevnik B, Anastassiadis K et al. Formation of pluripotent stem cells in the mammalian embryo depends on the POU transcription factor Oct4. Cell. 1998;95:379-391.

[11] Williams RL, Hilton DJ, Pease S et al. Myeloid leukaemia inhibitory factor maintains the developmental potential of embryonic stem cells. Nature. 1988;336:684-687.

[12] Niwa H, Burdon T, Chambers I et al. Self-renewal of pluripotent embryonic stem cells is mediated via activation of STAT3. Genes Dev. 1988;12:2048-2060.

[13] Matsuda T, Nakamura T, Nakao K et al. STAT3 activation is sufficient to maintain an undifferentiated state of mouse embryonic stem cells. EMBO J. 1999;18:4261-4269.

[14] Mitsui K, Tokuzawa Y, Itoh H et al. The homeoprotein Nanog is required for maintenance of pluripotency in mouse epiblast and ES cells. Cell. 2003;113:631-642.

[15] Chambers I, Colby D, Robertson M et al. Functional expression cloning of Nanog, a pluripotency sustaining factor in embryonic stem cells. Cell. 2003;113:643-655.

[16] Ivanova NB, Dimos JT, Schaniel C et al. A stem cell molecular signature. Science. 2002;298:601-604.

[17] Bhattacharya B, Miura T, Brandenberger R et al. Gene expression in human embryonic stem cell lines: unique molecular signature. Blood. 2004;103:2956-2964.

[18] Jochum W, Passegue E, Wagner EF. AP-1 in mouse development and tumorigenesis. Oncogene. 2001. 20:2401-2412.

[19] Wisdom R. AP-1: one switch for many signals. Exp. Cell Res. 1999;253:180-185.

[20] Chinenov Y, Kerppola TK. Close encounters of many kinds: Fos-Jun interactions that mediate transcription regulatory specificity. Oncogene. 2001;20:2438-2452.

[21] Shaulian E, Karin M. AP-1 as a regulator of cell life and death. Nat. Cell Biol. 2002;4:E131-136. 
[22] Dam H, Castellazzi M.. Distinct roles of Jun:Fos and Jun:ATF dimers in oncogenesis. Oncogene. 2001; 20:2453-2464.

[23] Jochum W, Passegue E, Wagner EF. AP-1 in mouse development and tumorigenesis. Oncogene. 2001; 20:2401-2412.

[24] Brusselbach S, Mohle-Steinlein U, Wang ZQ et al. Cell proliferation and cell cycle progression are not impaired in fibroblasts and ES cells lacking c-Fos. Oncogene. 1995;10(1): 79-86.
[25] Field SJ, Johnson RS, Mortensen RM et al. Growth and differentiation of embryonic stem cells that lack an intact c-fos gene. Proc Natl Acad Sci USA. 1992; 89(19):9306-10.

[26] Hilberg F, Wagner EF. Embryonic stem (ES) cells lacking functional c-jun: consequences for growth and differentiation, AP-1 activity and tumorigenicity. Oncogene. 1992; 7(12):2371-80.

Submitted: 18 June, 2007 Accepted after reviews: 11 October 2007 